\title{
AISLAMIENTO E IDENTIFICACIÓN DE MICROORGANISMOS CON POTENCIAL BIOFERTILIZANTE DE SUELOS ARROCEROS DEL DISTRITO DE RIEGO DEL RIO ZULIA, NORTE DE SANTANDER
}

Por:

Marilyn Tatiana Santos Torres' ${ }^{1}$, Marelys Tibisay Santos Torres', Diana Cárdenas Caro²

\section{RESUMEN}

Se evalúo la población microbiana de suelos cultivados con arroz en algunas zonas del Distrito de Riego del Río Zulia, Norte de Santander, Colombia, y suelos no cultivados con arroz. Se encontró que los suelos cultivados con arroz fueron significativamente bajos en poblaciones de hongos, bacterias y actinomicetos, comparados con los suelos no cultivados. Esta situación se debe posiblemente al excesivo laboreo y aplicación de pesticidas y al monocultivo al que se han sometido estos suelos arroceros por varios años. Por lo tanto, con el uso de microorganismos biofertilizantes, aislados en suelos de zonas con similares condiciones agroecológicas, favorecerá la adaptación de éstos microorganismos en la rizósfera y promoverán el reestablecimiento del equilibrio biológico e incremento de la actividad biótica de los suelos, mejorando la calidad y productividad de los cultivos. Un total de 43 bacterias y 4 hongos fueron aislados en diferentes suelos de esta zona de las cuales fueron identificados 25 microorganismos. Según los métodos de aislamiento, las bacterias se dividieron en dos grupos: diazotróficas, especies del género Azotobacter sp. Azospirillum sp. y Beijerinckia sp. y las solubilizadoras de fosfato inorgánico como, Bacillus megaterium, Bacillus cereus, Pseudomonas putida y Pseudomonas aeruginosa. Para la identificación de hongos se evaluaron las características micro y macroscópicas en el medio agar Czapeck siguiendo las claves fúngicas de Samson, Hoekstra y Oorsehot (1981) que permitió reconocer especies como Trichoderma sp., Aspergillus niger, Penicillium pupurogenum y Penicillium pinophyllum.
Palabras clave: Diazotróficas, fosfatosolubilizadores, bioferrtilizantes, banco de cepas.

\section{ABSTRACT}

It was evaluated the microbial population of soils cultivated with rice at some zones of the district of irrigation of Zulia River, Norte de Santander state, Colombia, and no cultivated soil with rice. It was found that the seeded soil with rice were significantly low in fungi, bacteria and actinomycete populations compared with no seeded with rice. This situation was due to possibly excessive use of agricultural machine and excessive application of pesticides and continuous rice monoculture. Therefore, with use the biofertilizer enriched with microorganism isolated from zone with similar agroecological conditions, will improve the microorganism adaptation of the rizosphere and will promote a reestablishment of the biological balance of soils and therefore to increase biotic activity improving the quality and productivity of the cultures. A total of 43 bacteria and 4 fungi were isolated in different soils of the studied zone, and were identified 25 microorganisms. According the isolation methodology, the bacteria were separate in two groups: diazotrophic like the species of the genera Azotobacter sp., Azospirillum sp. and Beijerinckia sp. and the phosphate solubilizate inorganic like Bacillus megaterium, B. cereus, Pseudomonas putida and $P$. aeruginosa. For the fungi identification were evaluate the micro and macroscopic characteristics in the culture medium Czapeck, following the fungi keys of Samson Hoekstra and Oorsehot (1981), which allowed recognize species like Trichoderma sp., Aspergillus niger, Penicillium purpurogenum, P. pinopilum.

Key words: Diazotrophics, phosphate solubilizate, culture pure, strains bank.

\footnotetext{
'Ingenieras de Producción Biotecnológica. Universidad Francisco de Paula Santander - UFPS. msantos410@hotmail.com, matisa410@yahoo.com

2 Ingeniera de Producción Biotecnológica. Facultad de Ciencias Agrarias y del Ambiente. Universidad Francisco de Paula Santander UFPS.dicarcaro@gmail.com
} 
Aislamiento e identificación de microorganismos con potencial biofertilizante de suelos arroceros del Distrito de Riego del Rio Zulia, Norte de Santander

\section{INTRODUCCIÓN}

En el Departamento Norte de Santander (Colombia), el cultivo del arroz ha tenido especial importancia no sólo por su impacto económico en la región, sino también, por sus repercusiones en el ámbito social, ya que el área de siembra anual está cercana a las 25.000 Ha con una producción alrededor de 16.800 ton de arroz paddy/año donde más del $90 \%$ del área arrocera se localiza en el Distrito de Riego del Río Zulia representando para la región progreso y desarrollo (FEDEARROZ, 2005). Sin embargo, el modelo de agricultura convencional que se practica actualmente en el agroecosistema arrocero, se ha caracterizado por el uso irracional de maquinaria agrícola y consumo de fertilizantes y pesticidas sintéticos que han desencadenado repercusiones medioambientales negativos manifestándose en el desequilibrio biológico del sistema edáfico al observarse un incremento de poblaciones de arvenses, fitopatógenos y plagas que afectan el desarrollo vegetal del cultivo y la población de microorganismos benéficos del suelo que participan activamente en la disponibilidad de nutrientes esenciales para las plantas. Todo esto se ha reflejado en bajos rendimientos por unidad de área, altos costos de producción, baja rentabilidad e insostenibilidad técnica y económica del sistema de producción más importante del Norte de Santander (Blanco, 2003). Por lo anterior, se realizó el aislamiento de microorganismos nativos de la zona del Distrito de Riego del Zulia, ya que estos son irremplazables en la transformaciones de la materia orgánica, y contribuyen en la formación del humus, la conservación de la estructura del suelo y la biodegradación de contaminantes (Hoffman et al., 2003). Según Van Elsas et al. (2002) y Anderson (2003), citados por Moratto, et al. (2005), los microorganismos influyen directamente sobre la fertilidad y productividad de suelos agrícolas, en particular, con respecto a la disponibilidad de nutrientes, la supresión de enfermedades para las plantas nativas así, como la degradación de diferentes plaguicidas, derivando de ellos energía y nutrientes para su metabolismo.
Estos microorganismos han sido objeto de estudios en la región del Espinal, en Tolima, donde se aislaron algunos bacterias de los géneros Azospirillum sp., Enterobacter sp., Azotobacter sp., Pseudomonas sp., Klebsiella sp., Alcalígenes faecalis, Azoarcus, Serratia $s p .$, cianobacterias y bacterias que oxidan azufre, quienes estimulan el crecimiento de las plantas al promover la erupción de raíces secundarias, actuando como protectores contra microorganismos fitopatógenos por la liberación de fitohormonas y sideróforos (Torres-Rubio, et al. 2000). Valero, (2000), identificó géneros bacterianos como Klebsiella sp., Enterobacter sp., Stenotrophomonas matophillia, Chromobacterium violaceum, Peudomonas sp., Azotobacter sp. y Azospirillum sp. en muestras de suelo de El Espinal, Saldaña en Tolima y Villanueva en Casanare. Estos fueron evaluados en su actividad biofertilizante en condiciones de invernadero, encontrando que contribuyen a mejorar la asimilación de fósforo y nitrógeno por las plantas, además de tener una alta eficiencia solubilizadora de fosfatos en el suelo, y calta capacidad de producir ácido indolacético, para estimular el crecimiento vegetal, al estimular el desarrollo de raíces, mejorando la eficiencia en la toma de nutrientes por parte de las plantas.

El objetivo de esta investigación fue aislar e identificar microorganismos nativos con potencial biofertilizante en suelos arroceros del Distrito de Riego del Río Zulia para la conformación del Banco de Cepas Biofertilizantes en el laboratorio de Bioprocesos de la Universidad Francisco de Paula Santander, que permitan desarrollar inoculantes biológicos para la restauración de estos suelos arroceros y posteriores investigaciones.

\section{MATERIALES Y MÉTODOS}

Diagnóstico de la población microbiana de los suelos en algunas zonas del Distrito de riego del río Zulia, Norte de Santander. Se tomaron muestras de suelo rizosférico en cultivos de arroz variedad Fedearroz 50 (10 - 15 días y 30 - 45 días de 
Aislamiento e identificación de microorganismos con potencial biofertilizante de suelos arroceros del Distrito de Riego del Rio Zulia, Norte de Santander

crecimiento), suelos en preparación y suelos no cultivados en las zonas de Restauración, Buena Esperanza y Limoncito, con el fin de evaluar su población microbiana, según el crecimiento en medios de cultivo agarizados de Glicerina para bacterias, almidón amoniacal para actinomicetos y Rosa de Bengala para hongos, mediante la técnica de diluciones seriadas en agua peptona estéril (Sánchez de P., 1990; Lorch et al.,1995 y Gómez, 1997) . Las muestras fueron tomadas en bloques al azar de $1 \mathrm{~m}^{2}$ en suelos no cultivados hasta obtener una mezcla compuesta de diez bloques. En suelos cultivados se utilizó en trayecto en " $X$ " tomando una muestra compuesta de sitios cada $5 \mathrm{~m}$. En ambos casos se tuvo en cuenta retirar la cobertura vegetal y muestrear en $15+/-5 \mathrm{~cm}$ de profundidad.

Aislamiento y caracterización de hongos y bacterias solubilizadoras de fosfato. El muestreo se realizó en la vereda de San José de la Vega ubicado en la zona Buena Esperanza. A partir de las muestras de suelo rizosférico recolectadas, se realizaron diluciones seriadas hasta $10^{-6}$, y se sembraron en el medio SRSM modificado para bacterias y para hongos solubilizadores de fosfato se empleó el medio SRS, según propuesto por Sundara, Rao y Sinha (1963). Estos últimos medios contienen sales de fosfatos de calcio y púrpura de bromocresol como indicador de $\mathrm{pH}$. Al cabo de 5 - 7 días se seleccionaron las colonias de bacterias y hongos que crecieron acidificando el medio de cultivo y formando un halo amarillo alrededor, indicando la actividad solubilizadora de fosfato.

Aislamiento y caracterización de bacterias diazotróficas. El muestreo se realizó en la zona correspondiente a Buena Esperanza, localizada en la parte central del Distrito, la cual es la más extensa con 4.350 hectáreas cultivadas de arroz bajo riego. De donde se tomaron muestras de suelo y plantas de arroz, variedad FEDEARROZ 50, en pleno crecimiento ( 1 2 meses de plantado) y la vereda Matecaña se tomaron muestras de suelos rizosféricos no cultivados. Se aislaron bacterias fijadores de nitrógeno por 4 metodologías diferentes buscando obtener la mayor representatividad de diazótrofos en suelo, rizósfera e interior de las plantas (endófitos). A continuación se describen los métodos empleadas para su aislamiento:

En el método 1, se realizaron diluciones seriadas sembrando en el medio Azotobacter medium y en medio Nfb y Rojo Congo agarizados. Por ser libres de nitrógeno son utilizados para seleccionar colonias morfológicamente típicas de especies de Azotobacter sp. y Azospirillum sp. respectivamente. En el método 2 , se hizo siembra directa de granos de suelo rizosférico sobre el medio de cultivo sólido selectivo de Azotobacter médium. En el método 3, se tomaron muestras de raíces de plantas de arroz de cada cultivo para realizar el proceso de desinfección y finalmente macerarlas en un mortero estéril con el fin de obtener bacterias diazotróficas endófitas, Se siembran por el método de agotamiento en medios de cultivos sólidos selectivos de Nfb y Azotobacter médium, totalmente libres de $\mathrm{N}$ mineral. Finalmente, en el método 4 se desarrolló el procedimiento de aislar Azospirillum sp. a partir de raíces frescas esterilizadas superficialmente. Este método, consiste en cortar las raíces desde la base del tallo, hasta conseguir una medida de 3 $\mathrm{cm}$ de longitud para luego desinfectarlas. Posteriormente se sembraron estas raíces en frascos pequeños que contienen medio semisólido de Nfb y del medio selectivo de Azospirillum amazonense semisólido. Ambos medios empleados carecen de nitrógeno según Renie 1988, y es clave para el aislamiento de un gran número de microaerófilos diazotróficos asociados a las raíces.

Identificación bioquímica de las bacterias con potencial biofertilizante. De acuerdo a los resultados obtenidos en los diferentes aislamientos para cada grupo se procedió a la caracterización microscópica y tintorial. Las colonias seleccionadas se repicaron en agar nutritivo para realizarles tinción de Gram y de esporas con verde de malaquita a las que resultaron ser Gram positivas. De acuerdo a las características definidas para cada grupo de aislamiento, realizaron pruebas bioquímicas que corresponden al grupo 
Aislamiento e identificación de microorganismos con potencial biofertilizante de suelos arroceros del Distrito de Riego del Rio Zulia, Norte de Santander

de bacilos formadores de esporas y cocos Gram positivos (Bacillus sp.), Bacilos y cocos gram negativos (Pseudomonas sp. y Azotobacter sp.) y Bacilos vibroides Gramnegativos / microaerofílicos helicordales/ aeróbicas (Azospirillum sp.) descritos en el manual de Bergey, 1984. Además, se desarrolló la evaluación de la producción de pigmentos fluorescentes por los bacilos Gram negativos, pues se espera encontrar rizobacterias del género Pseudomonas sp. que correspondan a especies de Pseudomonas fluorescens y Pseudomonas putida, teniendo en cuenta el interés biofertilizante como promotoras del crecimiento vegetal (PGPRs) para la conformación del cepario. Esta evaluación se desarrolló a través de los medios agarizados King A (o Pseudomonas Agar P) que potencia la elaboración de piocianina que solamente es producida por $\mathrm{P}$. aeruginosa, mientras que el King B (o Pseudomonas Agar F) potencia la elaboración de fluoresceína e inhibe la de piocianina. Estos pigmentos son solubles en agua y difunden al medio. La piocianina es un pigmento azul - verde mientras que la fluoresceína o pioverdina es amarillo - verdoso y fluoresce cuando es expuesto a la luz UV (Valerica, et al. 2000).

Realización de pruebas bioquímicas mediante el sistema de identificación rápida BBL CRYSTAL. Este procedimiento se realizó a las cepas bacterianas solubilizadoras de fosfatos y a los aislamientos de bacterias diazótroficas preseleccionados, lo que permitirá la confirmar la identificación de las cepas y los aislamientos estudiados durante la investigación, corroborando los procedimientos desarrollados en las baterías bioquímicas y contribuyendo con pruebas adicionales que serán tenidas en cuentas para aquellos grupos bacterianos que no pueda ser identificados por la base de datos del sistema BBL CRYSTAL.

Identificación macro y microscópica de hongos. Los hongos estudiados se repicaron en Agar Czapeck a una temperatura de $25+2^{\circ} \mathrm{C}$ por 3 a 5 días o más si la cepa lo requiere, para realizar la tinción con azul de lactofenol e identificarlas mediante las claves de Samson, R. A., Hoeskstra, E. S., y Oorsehot, C. (1981).

\section{RESULTADOS Y DISCUSIONES}

Diagnóstico de la población microbiana de los suelos en algunas zonas del distrito de riego del río Zulia, Norte de Santander. Esta evaluación permitió comparar la incidencia de la actividad de fangueo, monocultivo, aplicación de agrotóxicos y demás actividades de la agricultura convencional en la población microbiana de los suelos arroceros en las zonas agroecológicas Limoncito, Buena Esperanza y Restauración. El número de unidades formadoras de colonias por gramo de suelo seco (UFC/gr de suelo seco) presente en suelos cultivados y de las zonas estudiadas tal como se observa en la Figura 1, refleja el bajo componente biótico con una población microbiana inferior del orden de $10^{2}$ UFC/ gr suelo seco. En contraste se encontró que en suelos no cultivados con arroz en las zonas estudiadas, la población microbiana es evidentemente superior especialmente la población bacteriana (orden de $10^{5}$ UFC/ gr suelo seco) seguido de los hongos (orden de $10^{4}$ UFC/ gr suelo seco), lo que indica claramente que la microbiota natural del suelo se ve afectada por la forma en que se lleva a cabo los sistemas de producción del arroz y que eventualmente, está afectando las condiciones edafoclimáticas que alteran los factores biológicos y físico-químicos de los suelos y por lo tanto, la productividad de los cultivos. Estos resultados coinciden con los reportados por Wardle, et al. (1994), Nielsen y Winding (2002) y Moratto et al. (2005), en suelos cultivados con la aplicación de agroquímicos como fertilizantes y plaguicidas. Según la prueba de dependencia (Ji Cuadrado) de la variable en estudio, que fue la población microbiana (hongos, bacterias y actinomicetes) y los diferentes manejos de los suelos analizados (cultivados en monocultivo por más de 30 años, y suelos sin cultivar), se encontró una alta dependencia con un grado de error de 0,01, utilizando el programa estadístico Biometry versión 2.2, lo que comprueba que el número de microorganismos en el suelo es dependiente 
Aislamiento e identificación de microorganismos con potencial biofertilizante de suelos arroceros del Distrito de Riego del Rio Zulia, Norte de Santander

del manejo que se presente en ellos, por lo que la disminución de maquinaria y agroquímicos podrían disminuir el impacto negativo sobre la población de microbiota nativa en estos suelos arroceros.

Caracterización de los aislamientos de bacterias solubilizadoras de fosfatos. Se obtuvieron colonias de tamaño y coloración variables que van desde transparentes a blancas, algunas producen pigmentos de color amarillo y verdoso azulado difusible en el medio que exhibe fluorescencia bajo la luz U.V. Se destacaron formas pleomórficas en bacterias que no son de interés biofertilizante como cocos gramnegativos y de esta forma sólo se obtuvo un pequeño grupo de bacterias bacilares gramnegativos, y grampositivos (esporulados o no). De acuerdo a las caracterizaciones de las colonias se conformaron dos grupos funcionales: las bacterias solubilizadoras de fosfatos Grampositivas y las bacterias solubilizadoras de fosfatos Gram negativas para realizar las pruebas bioquímicas pertinentes a cada grupo en estudio.

Figural. Población microbiana de los suelos muestreados en el Distrito de Riego del Río Zulia, 2004.

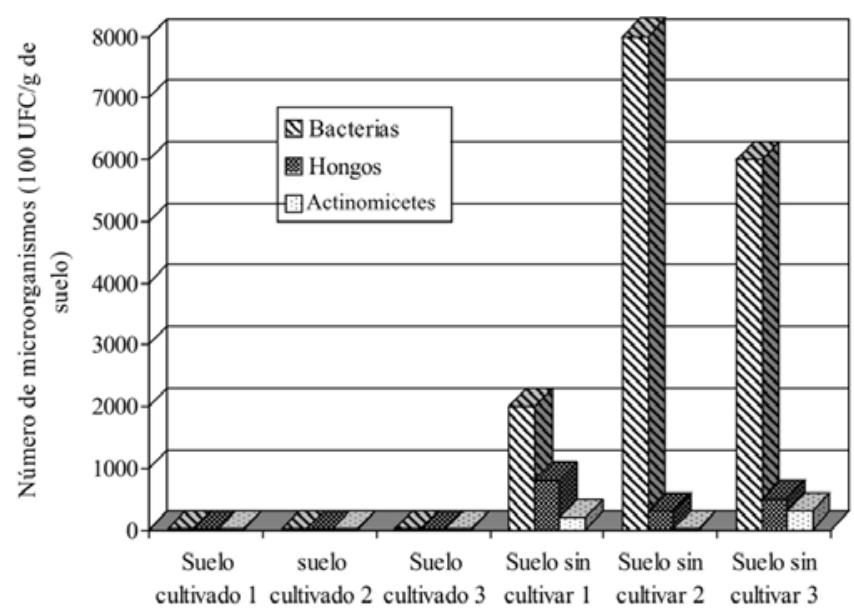

Caracterización de bacterias diazotróficas. Se presentaron bacterias Gram negativas, bacilos cortos, formas ovoides y otras pleomórficas. También se encontraron células unidas a otras por sus extremos formando cadenetas. Dentro de sus características macroscópicas se visualizaron diversos tipos de colonias de tamaños muy variables (desde puntiforme a irregulares) cuya coloración varía desde transparentes a blanco y amarillo y algunas con bordes filamentosos, aunque la mayoría de las colonias muestran bordes lisos, de consistencia viscosa, cremosa y brillante.

Identificación bioquímica de las bacterias con potencial biofertilizante. Se seleccionaron los aislamientos de la Tabla 1 para la caracterización bioquímica, pues los demás no pudieron ser nuevamente repicados en condiciones in Vitro.

Tabla 1. Aislamientos bacterianos seleccionados para la identificación bioquímica.

\begin{tabular}{|c|c|l|}
\hline Aislamiento & Medios de cultivo & \multicolumn{1}{|c|}{ Tinción } \\
\hline 7 & SRSM & Bacilo corto Gramnegativo \\
9 & SRSM & Bacilo Grampositivo Espora + \\
16 & Glicerina & Bacilo Gramnegativo \\
20 & Ashby & Bacilo Grampositivo Espora+ \\
15 & Ashby & Bacilo corto Gramnegativo \\
$16 a$ & Azotobacter medium & Bacilo corto Gramnegativo \\
31 & Azotobacter médium & Bacilo corto Gramnegativo \\
$7 a$ & $\mathrm{Nfb}$ & Bacilo corto Gramnegativo \\
$21 a$ & $\mathrm{Nfb}$ & Bacilo corto Gramnegativo \\
\hline
\end{tabular}

De acuerdo a las pruebas bioquímicas realizadas para el grupo de bacilos formadores de espora y cocos Gram positivos se pudo deducir que la cepa 9, según el "criterio máximo" corresponde a la especie de B. megaterium con un porcentaje de confianza de $98 \%$ en el test de BBL CRYSTAL. La cepa 20 según resultados obtenidos correspondió a especies de Bacillus sp., aproximándose bioquímicamente a Bacillus cereus, de acuerdo al test de identificación rápida de $\mathrm{BBL}$ CRYSTAL. Sin embargo, es importante reconocer que esta especie es similar bioquímicamente con Bacillus thuringiensis a la cual se ha categorizado dentro del mismo grupo, pero su diferencia se ha descrito por la formación del cristal parasporal por esta última, lo que le permite considerarse como una especie entomopatógena (Erazo, 2003). 
Aislamiento e identificación de microorganismos con potencial biofertilizante de suelos arroceros del Distrito de Riego del Rio Zulia, Norte de Santander

Las cepas 7 y 16 por presentar pigmentación amarilla sobre el medio, se evaluó en agar Cetrimide para determinar la fluorescencia característica de Pseudomonas sp. El aislamiento 7 presentó crecimiento y una pigmentación amarilla y la cepa 16 también tuvo crecimiento en este medio, pero mostrando pigmentación azul verdosa, lo cual llevó a deducir que estas dos cepas pertenecían a especies de Pseudomonas sp. Según el crecimiento en King A y King $B$, se observó en la cepa 7 una pigmentación intensa de color amarillo en el medio King $A$, al igual que en el medio King $B$ debido a la pioverdina que es un sideróforo quelador de hierro $\mathrm{Fe}^{3+}$ característico de las especies de Pseudomonas putida y Pseudomonas fluorescens, y la cepa 16 en King A presentó una pigmentación verde azulada no tan intensa como en el medio King B debido a la presencia de piocianina que también es un sideróforo que actúa como un secuestrador de $\mathrm{Fe}^{3+}$ en medios carentes de este elemento. Esta pigmentación es característica de Pseudomona aeuroginosa (Torres-Rubio, et al. 2000; Valerica, et al. 2000; Valero, 2000).

Para el reconocimiento de las bacterias del género Azotobacter sp., se pueden emplear medios de cultivos variados y simples solo con la característica de ser absolutamente libre de nitrógeno, con la frecuente utilización de manitol en la elaboración de los medios de cultivos, como en el medio Ashby sobre el cual se observó su crecimiento de los aislamientos como colonias lisas, transparentes (Novo, 1993).

Finalmente, se utilizó el medio mineral libre de nitrógeno con glucosa como fuente de carbono y calcio en forma de $\mathrm{CaCO}_{3}$ requerido en algunas especies de Beijerinckia sp. para la fijación del $\mathrm{N}_{2}$ y poco inhibidor para las especies de Azotobacter sp. El $\mathrm{CaCO}_{3}$ puede ser reemplazado, por $\mathrm{CaCl}_{2}$ (Döbereiner, et al., 1995, Becking, 1998). Sin embargo, las únicas cepas que presentaron un buen crecimiento fueron los aislamientos 15 y $16 \mathrm{a}$. El crecimiento se destacó por sus colonias viscosas y transparentes, lo cual confirmó la presencia de Azotobacter sp. o Beijerinckia sp., siendo clave la realización de la prueba que reveló la formación de quistes en un medio libre de nitrógeno con 1 butanodiol, lo cual diferencia a Azotobacter sp. de las especies de Beijerinckia sp., que además, presentó un crecimiento viscoso y elástico que al tomar con el asa microbiológica parte de su colonia es retirada (Becking, 1998). Para la identificación de bacterias fijadoras de nitrógeno, se desarrollaron las pruebas bioquímicas obteniendo que los aislamientos pueden corresponder según su "proximación máxima" más cercano a los géneros Azotobacter sp. (Aislamiento 31), Beijerinckia sp. (aislamiento 16a) y Azospirillum brasilense (aislamiento 7a) y Azospirillum lipoferum (aislamiento 21 a).

Identificación macroscópica y microscópica de hongos. Para la identificación de los hongos en el laboratorio se realizó una evaluación macroscópica de cada cepa en agar Czapeck teniendo en cuenta su forma de crecimiento, el cambio de color del micelio aéreo y la pigmentación del medio o presencia de exudados superficiales, con la consecuente observación microscópica donde se pudo evaluar la morfología de las diferentes estructuras que conforman el cuerpo fructífero del hongo y así clasificarlo según la descripción de Samson, R. A., Hoekstra, H. S. y van Oorschot, C. (1981).

El aislamiento 1, en agar Czapeck presentó un crecimiento de forma polvorienta y color verde aceituna durante los días de incubación sin la presencia de pigmentos o exudados en la superficie del medio, característico del género Trichoderma sp., con la presencia de conidióforos piramidales largos con repetidas fiálides cortas en forma de botella, donde se sostiene en el ápice las conidias agrupadas entre sí (Samson, et al. 1981). El aislamiento 2 presentó un abundante crecimiento en Agar Czapeck de color amarillo verdoso opaco intermezclado con los conidióforos grises cuando maduran sus colonias. Microscópicamente las conidiosporas tienen el aspecto de un pequeño pincel característico del género Penicillum sp., clasificado dentro del grupo de los 
Aislamiento e identificación de microorganismos con potencial biofertilizante de suelos arroceros del Distrito de Riego del Rio Zulia, Norte de Santander

Penicillum asimétricos ya que poseen un conidióforo que se ramifica una o dos veces quebrando la simetría con una apariencia velutina, es decir colonias con aspecto de un vello aterciopelado sin la presencia de exudados o pigmentos sobre el medio. Estas características identifican a este aislamiento como Penicillum pinophyllum (Stammati et al. 2002). Por otra parte, el aislamiento 4 al igual que la anterior se clasificó dentro del género de los Penicillum sp., por su morfología microscópica observada, pero en el grupo de los Penicillum biverticilado simétrico al poseer dos verticilios: métula y esterigma. No presenta rama. Sus colonias son de colores variables finalizando en tonos de color amarillo - anaranjado a rojizo con exudados superficiales del mismo color debido a la producción de un pigmento que se difunde sobre el agar Czapeck, como consecuencia de algunas sustancias o ácidos productos del metabolismo (Samson, et al. 1981). Esta pigmentación soluble rojizo en el medio, hace que este aislamiento se identifique como un P. purpurogenum, característico por la producción de metabolitos tóxicos que alteran las funciones normales de células humanas o animales produciendo cáncer por la ingestión de alimentos contaminados por esta micotoxina llamada Rubratoxina B frecuentemente aislados en cereales como el arroz, trigo y semillas de soya (Natori et al., 1970). Finalmente el aislamiento 3 forma colonias blancas al comienzo, donde más tarde se va cubriendo de puntos negros debido a las esporas negras que producen este pigmento. Microscópicamente presenta dos filas de esterigma que producen ácidos orgánicos, principalmente glucónico, cítrico y oxálico, además, predomina una vesícula apical donde sobresalen las fiálides dispuesto en forma radial sobre la cabeza conidial distribuidos en columnas. Tanto su crecimiento y morfología pertenecen a la especie de Aspergillus niger (Samson, et al. 1981).

\section{CONCLUSIONES}

El manejo de los cultivos, influye directamente en la población microbiana de los suelos, disminuyendo la actividad biológica que es fundamental para la sostenibilidad productiva de los suelos agrícolas.
Se identificaron microorganismos con potencial biofertilizante de suelos cultivados con arroz, especialmente de los géneros bacterianos diazotróficos de Beijerinckia sp., Azotobacter sp. y Azospirillum sp. y solubilizadores de fósforo como Bacillus megaterium, y Pseudomonas putida, pese a que estos suelos, han sido trabajado en monocultivo desde hace más de 30 años bajo sistemas de fangueo y grandes aplicaciones de agroquímicos, lo que podría llevar a deducir que es posible que estos aislamientos estén adaptados a estas condiciones de supervivencia y puedan expresar un mayor efecto en la fertilización biológica del cultivo en comparación con cepas foráneas o de otros suelos menos afectados. Estas bacterias, son consideradas promotoras de crecimiento vegetal, por su actividad fijadora de nitrógeno, solubilización de fosfatos, síntesis de vitaminas hy fitohormonas. Además se encontró una población de hongos que poseen habilidades de producir enzimas lignocelulósicas que mejoren y potencialicen la degradación físico-química de residuos vegetales de la agricultura, e incorporarlos al suelo en la fase de preparación mejorando las concentraciones de materia orgánica. Este es el caso de Trichoderma sp., Aspergillus niger y Penicillium pinohyillum. De igual forma, también son muy eficientes en la solubilización de fósforo, nutriente que se ha presentado a través de los años en muy baja disponibilidad en los suelos, lo que deriva en el no aprovechamiento por parte de la planta, y el incremento del suministro de fertilizantes fosforados, tratando de remediar su deficiencia en los suelos.

De acuerdo a esto, los aislamientos obtenidos podrán ser utilizados en la producción de inoculantes microbianos para su aplicación y evaluación en campo en el cultivo de arroz del departamento Norte de Santander, siendo éste un estudio exploratorio en la región, ya que no se ha determinado aún, el potencial biofertilizante de aislamientos autóctonos. Sin embargo, es necesario tener en cuenta en su aplicación en campo, algunas prácticas culturales de preparación del suelo y control de plagas y enfermedades, pues estos son aspectos que inciden directamente en la 
Aislamiento e identificación de microorganismos con potencial biofertilizante de suelos arroceros del Distrito de Riego del Rio Zulia, Norte de Santander

colonización y permanencia de los inoculantes en el suelo, ya que una aplicación desmedida de estos microorganismos también puede desequilibrar el agroecosistema y además, crear dependencia de insumos biológicos, lo cual no permitiría la búsqueda de la sostenibilidad en el este sector productivo agropecuario. Por lo tanto, se logró obtener el cepario de microorganismos biofertilizantes en el laboratorio de Bioprocesos de la Universidad Francisco de Paula Santander, con aislamientos nativos bacterianos del género Azotobacter sp., Azospirillum sp., Beijerinckia sp., Bacillus megaterium, Pseudomonas putida, y hongos como Trichoderma sp., Aspergillus niger y Penicillium pinohyillum.

\section{BIBLIOGRAFÍA}

BERGEY. 1984. Manual of Systematic Bacteriology. William and Wilkins Eds. Baltimore, USA.

BECKING, J. H. 1998. The Genus Beijerinckia. En: http://141.150.157.117:8080/prokPUB/chaphtm/ $110 / 01$ 00.htm

BLANCO, S., J.O. 2003 Manejo Integral de Suelos con énfasis en el Cultivo del Arroz. OFFSET la Opinión. Cúcuta. Colombia.126p

CANAVARRO, A and MACHADO, S. de P. 2002. Sideróforos: uma resposta dos microorganismos. Universidade Federal do Río de Janeiro. Ed. Quim Nova, volumen 25. Rio de Janeiro.

ERAZO, J. P. 2003. Monografía de Bacillus thuringiensis. Laboratorio Biocontrol. Palmira, Colombia.

FEDEARROZ, 2005. Tomado de la revista Arroz. Publicación Vol. 53 No. 455. Bogotá, D.C., Colombia.

GOMEZ L., E. 1997. Estimación de algunos agentes biológicos del suelo asociados con el manejo del cultivo de la yuca Manihot esculenta Crantz, en la costa norte de Colombia. Tesis de Maestría. Universidad Nacional de Colombia, Sede Palmira, 98p.

HOFFMAN, J., J. BEZCHLEBOVÁ, L. DUSEK, L. DOLEZAL, I. HOLOUBEK, P. ANDEL, A. ANSORGOVÁ y S. MALY. 2003. Novel approach to monitoring of the soil biological quality. Environ. Intl. 28, 771-778.

KONEMAN, E., 2001. Diagnóstico Microbiológico, Texto y Atlas color. Editorial Médica Panamericana, Quinta Edición. Madrid, España. 85p.

LORCH, H. J.; BENCKIESER, G and O. J. C. G. 1995. Basic methods for counting microorganisms in soil and water In: ALEF; K y NANNIPIERI, P (edit). Methods in applied soil Microbiology and Biochemistry. Academic Press Limited. London. $889 p$

MORATTO, C., MARTíNEZ, L. J., VALENCIA, H. y SÁNCHEZ, J. 2005. Efecto del uso del uso del suelo sobre hongos solubilizadores de fosfato y bacterias diazotróficas en el páramo de Guerrero (Cundinamarca). Agronomía Colombiana. 23(2): 299-309.

NATORI, S., SAKAKI, S., MURATA, H., UDAGAWA, S., ISHINOE, M., SAITO, M., UMEDA, M. y OHTSUBO, A. 1970. Production of rubratoxin B by Penicillium purpurogenum Stoll. Applied Microbiology 19(4): 613-617.

NIELSEN, M.N y A. WINDING. 2002. Microorganisms as indicators of soil health. Technical report (388). National Environmental Research Institute, Denmark. 84 p.

NOVO, R. 1993. Microbiología del suelo y biofertilización. En: Memorias de la Fundación de Asesorías para el Sector Rural (FUNDASES). Santa fe de Bogotá. 101 pp.

PAZOS, M.; HERNANDEZ, A,; PANEQUE $M$. et al. 2000. Caracterización de cepas del género 
Aislamiento e identificación de microorganismos con potencial biofertilizante de suelos arroceros del Distrito de Riego del Rio Zulia, Norte de Santander

Azospirillum aislados de dos tipos de suelo de la localización de San Nicolás de Bari. UFT. Cuba.

SAMSON, R. A., Hoekstra, E. S. y Van Oorschot, C. Introduction to Food-Borne Fungi. Centraalbureau Voor Schimmelcultures, 1981.

SÁNCHEZ de P. M.; MARMOLEJO de la T., F.; BRAVO, N. 2000. Microbiología. Aspectos Fundamentales. Universidad Nacional de Colombia, Palmira, 300p.

STAMMATI, A. L.; NICOLETTI, R.; SALVATORE, de E, et al. 2002 Las características citoestáticas de un compuesto de la novena derivación del Penicillum pinophylum: un estudio in vitro. Instituto Sperimentale por el Tabacco. Scatati, Italia.

SUNDARA, R. \& S, 1963. Organisms phosphate solubilizers in soil. Indian Journal of Agriculture Science. P. 272-278.

TORRES-RUBIO, M., VALENCIA-PLATA, S., BERNALCASTILLO, J., MARTÍNEZ-NIETO, P. 2000. Isolation of Enterobacteria, Azotobacter sp. and Pseudomonas sp., Producers of Indole-3-Acetic Acid and Siderophores, from Colombian Rice Rhizosphere. . Revista Latinoamericana de Microbiología 42:171-176.

VALERICA C.P., Z.; DE POLLI, H.; G., N. 2000. Pseudomonas spp. Fluorescentes - bacterias promotoras de crecimiento de plantas e Biocontroladoras de fitopatógenos em sistemas de ProduVao Agrícola. Seropedica: Embrapa Agrobiología. Brasilia.

VALERO, N.O. 2000. Potencial biofertilizante de bacterias diazotrofas y solubilizadoras de fosfatos asociadas al cultivo de arroz (Oryza sativa L.). Tesis Maestría en Microbiología. Universidad Nacional de Colombia. Bogotá D.C.
WARDLE, D.A., K.S. NICHOLOSON y A. RAHMAN. 1994. Influence of herbicide applications on the decomposition, microbial biomass, and microbial activity of pasture shoot and root litter. New Zealand J. Agr. Res. 37, 29-39.

Recibido: Febrero 28 de 2006

Aceptado: Diciembre 10 de 2006 